Contract No. and Disclaimer:

This manuscript has been authored by Savannah River Nuclear Solutions, LLC under Contract No. DE-AC09-08SR22470 with the U.S. Department of Energy. The United States Government retains and the publisher, by accepting this article for publication, acknowledges that the United States Government retains a non-exclusive, paid-up, irrevocable, worldwide license to publish or reproduce the published form of this work, or allow others to do so, for United States Government purposes. 
ASME 2011

Pressure Vessels and Piping Conference July 17-21, 2011, Baltimore, Maryland, USA

PVP2011-57011

\section{STATISTICAL SAMPLING FOR IN-SERVICE INSPECTION OF LIQUID WASTE TANKS AT THE SAVANNAH RIVER SITE}

\author{
Lindsay R. Baxter \\ Savannah River National Laboratory \\ Aiken, South Carolina, USA
}

\author{
Stephen P. Harris \\ Savannah River National Laboratory \\ Aiken, South Carolina, USA
}

\begin{abstract}
Savannah River Remediation, LLC (SRR) is implementing a statistical sampling strategy for In-Service Inspection (ISI) of Liquid Waste (LW) Tanks at the United States Department of Energy's Savannah River Site (SRS) in Aiken, South Carolina. As a component of SRS's corrosion control program, the ISI program assesses tank wall structural integrity through the use of ultrasonic testing (UT). The statistical strategy for ISI is based on the random sampling of a number of vertically oriented unit areas, called strips, within each tank. The number of strips to inspect was determined so as to attain, over time, a high probability of observing at least one of the worst $5 \%$ in terms of pitting and corrosion across all tanks. The probability estimation to determine the number of strips to inspect was performed using the hypergeometric distribution. Statistical tolerance limits for pit depth and corrosion rates were calculated by fitting the lognormal distribution to the data. In addition to the strip sampling strategy, a single strip within each tank was identified to serve as the baseline for a longitudinal assessment of the tank safe operational life. The statistical sampling strategy enables the ISI program to develop individual profiles of LW tank wall structural integrity that collectively provide a high confidence in their safety and integrity over operational lifetimes.
\end{abstract}

\section{NOTATIONS}

ASME: American Society of Mechanical Engineers

CCP: Corrosion Control Program

ISI: In-Service Inspection

LANL: Los Alamos National Laboratory

LP: Lower Plate

LW: Liquid Waste

MP: Middle Plate
$\mathrm{M}_{\mathrm{X}} \mathrm{PD}$ : Maximum pit depth (mils) per 1 foot segment on a strip.

P-Scan: Projection Image Scanning

SRNL: Savannah River National Laboratory

SRR: Savannah River Remediation LLC

SRS: Savannah River Site

UP: Upper Plate

UT: Ultrasonic Testing

UT-SSP: UT Statistical Sampling Plan

\section{INTRODUCTION}

Liquid Waste (LW) has been stored in underground carbon steel tanks at the United States Department of Energy's Savannah River Site (SRS) in Aiken, South Carolina since the 1960s. To ensure the safe storage of LW, the tank structures must provide confinement via a leak-tight barrier to the environment. Additionally, the tanks must maintain acceptable structural stability during design basis events, including loads from both normal service and abnormal (e.g., seismic) conditions. Buried underground in steel and cement vaults, individual tanks are enormous in size (Figure 1,2), with diameters of approximately 85 feet and heights of approximately 33 feet (Figure 3 ). The storage capacity for individual tanks is approximately 1.3 million gallons. During service life, the tanks contain varying volumes and constitutions of LW. In the process of remediation and disposition of LW, tanks will be emptied, cleaned, grouted, and permanently sealed. The inspection of structural integrity of the tanks providing a real-time assessment of actual conditions while in service is imperative, but bears logistical challenges intrinsic to underground tanks. Risers provide limited access (Figure 4), and structural supports interfere at times with surface area and directionality of instrumental inspections. 


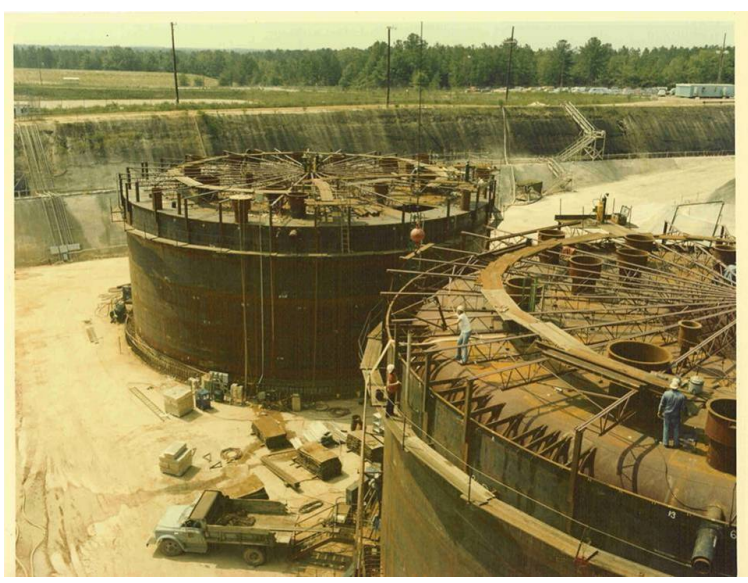

Figure 1: Type III LW Tank under Construction during the 1960s.

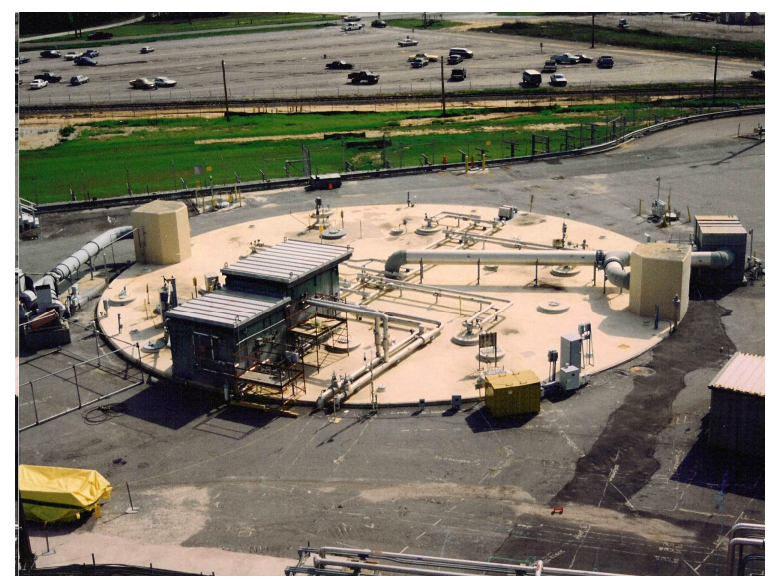

Figure 2: Top View of An Underground Type III LW Tank.

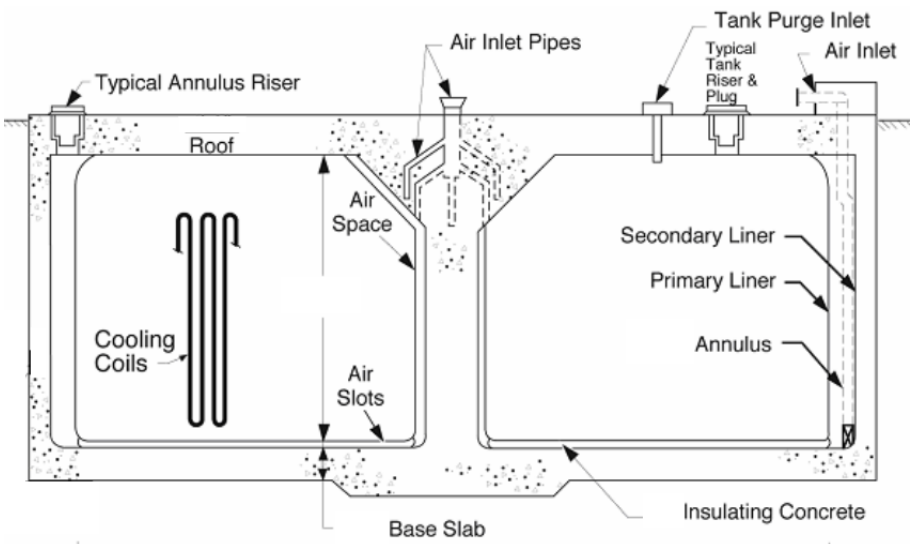

Figure 3: Cut-Away Drawing of An Underground Type III LW Tank.

SRS implemented a corrosion control program (CCP) for the LW tanks in 1977 to mitigate general corrosion, pitting corrosion, and stress corrosion cracking of the carbon steel structures. The program requires that minimum levels of corrosion inhibitors (e.g., sodium hydroxide and sodium nitrite) be maintained in the liquid portion of the waste and that maximum allowable interior temperatures are not exceeded. If these requirements are met, general corrosion rates and the risk of pit initiation are expected to be low. However, deviations from ideal chemistries could occur, for example, when waste is transferred between tanks. The carbon steel thinning due to degradation (e.g. pitting or corrosion) would reduce the original confinement capacity of the LW tanks. The majority of the tanks have been in compliance with the corrosion control program since being placed in service.

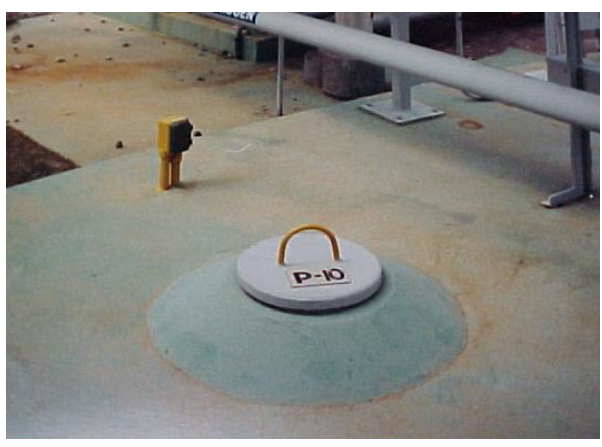

Figure 4: Riser Access Port.

An In-Service Inspection (ISI) program, begun in 1971 at SRS, is used to assess the structural integrity of the tanks and to confirm that the CCP is effectively mitigating corrosion. The ISI program focuses on ultrasonic (UT) inspection of the LW tanks. All UT inspections are performed using the projection image scanning (P-Scan) automated ultrasonic testing device, which is remotely operated on a magnetic wall crawler (Figure 5a, 5b). The inspections focus on gathering data related to the primary corrosion mechanisms of concern: general corrosion, pitting corrosion, and stress corrosion cracking. No cracking has been found in Type III/IIIA LW tanks.

Due to the high cost and time constraint of inspecting even a portion of a single tank, a statistical sampling strategy was implemented to account for variations in the materials of construction, tank chemistry, and measurement uncertainty.

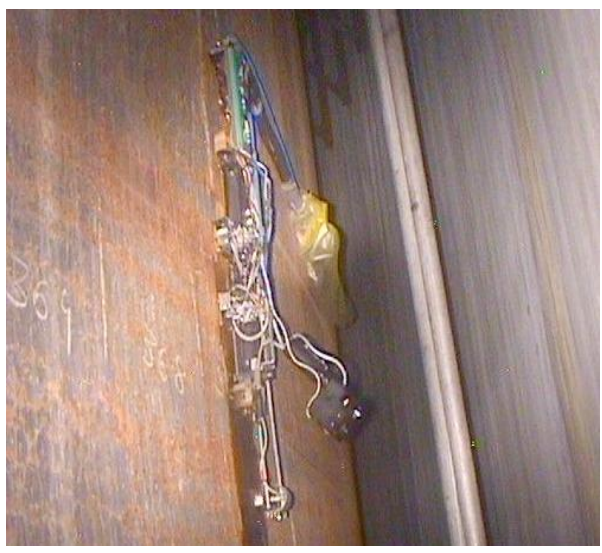

Figure 5a: In-use UT Wall Crawler with P-Scan Device. 


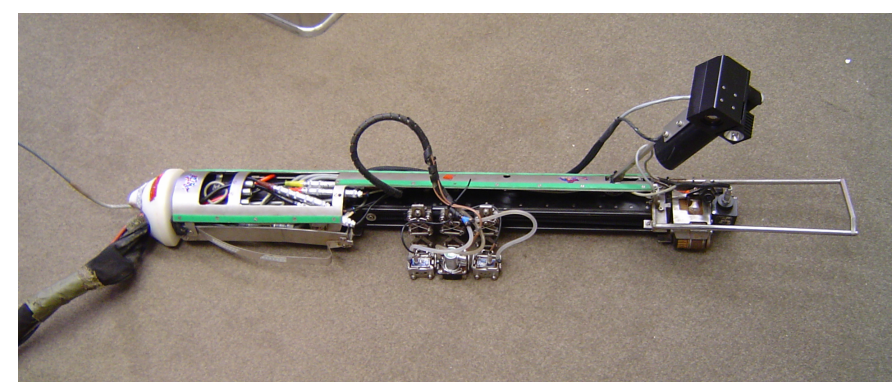

Figure 5b: Top view of the Wall Crawler with P-Scan Device.

Our strategy is to employ an inspection criterion for LW tanks similar to that indicated in DOE-STD- $3013^{1}$ for packaging and storage of excess plutonium from the U.S. nuclear weapons program. The standard directed that a surveillance plan be developed and used for monitoring the condition of the 3013 containers during storage. As a result, Los Alamos National Laboratory (LANL) in New Mexico developed the statistical strategies reported in the "Selection of 3013 Containers for Field Surveillance" ${ }^{2}$.

By expanding and modifying the LANL strategy for 3013 containers, the ISI program aims to produce high confidence in the structural integrity and safety of the in-service Type III/IIIA LW tanks. This report outlines the statistical sampling strategy for ISI of these underground tanks at SRS.

\section{BACKGROUND ON STATISTICAL SAMPLING STRATEGY}

As part of the surveillance program for the 3013 containers, LANL has put forth a statistical sampling strategy for the 3013 containers that have structure and contents that are classifiable by way of laboratory tests on pedigree materials and that have container loading history. The 3013 containers are subjected to a decision tree process for classification based on their risk potential. As per the LANL plan, a container is classified (binned) according to how its safety/integrity may be challenged through pressurization and/or corrosion.

The statistical sampling strategy for evaluating the safety/integrity of the 3013 container population states that a sample should be random and large enough to attain a $99.9 \%$ probability (also called "confidence") of observing at least one of the worst $5 \%$ of the containers under study, denoted as $99.9 \% / 5 \%$.

UT has been conducted periodically on the external surfaces of the primary tanks mainly near adjacent risers. The UT data include wall thickness and pit depth measurements. Starting in 1975, wall thickness was measured with UT, but pit depth was not typically measured prior to 1983 . The LANL 3013 statistical sampling strategy was adapted for the ISI program to determine the area to inspect across the ISI tanks, and the new SRS sampling strategy will henceforth be referred to as the "UT Statistical Sampling Plan" (UT-SSP).

\section{THE STATISTICAL SAMPLING PLAN}

The purpose of the UT-SSP is to improve the credence and spatial application of current inspection results, with the goal of verifying tank integrity throughout service life. The UT-SSP is based on UT inspection of vertically oriented unit areas called "strips." A strip is typically 8.5 " wide $(0.27 \%$ of the tank circumference) and covers the accessible height of the primary tank wall, including areas on the top and bottom knuckles (Figure 6). Within each strip, an inherently random collection of areas from the lower, middle, and upper plates is characterized.

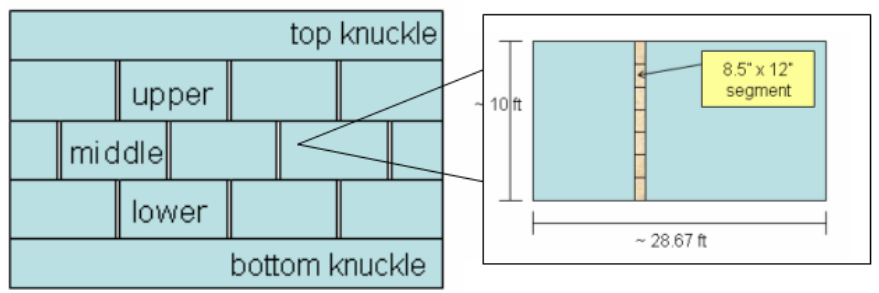

Figure 6: Left Side: Profile of a LW Tank Wall, Right: Profile of a Typical Plate.

The intent of the strip selection is to develop statistical confidence in the CCP's ability to mitigate pitting and thinning of the inner wall of the LW tanks. Strip selection is stratified by quadrant, with a minimum of four strips randomly selected per tank for each scheduled inspection. In addition, during each scheduled inspection, one static "baseline" strip per tank that has been previously inspected will be inspected again. The baseline strip will provide a basis for trending corrosion rates and developing service-life projections.

Like the 3013 statistical sampling strategy, the UT-SSP approach requires no assumptions about which specific strips or tanks are the "worst." Assumptions targeting tanks or strips within specific tanks for UT inspection could introduce bias, especially across a population of tanks of this size with variable service-life contents. However, due to the large surface area, it is necessary to define a criterion for determining one of the worst strips within any particular LW tank for efficient utilization of UT resources. The objective of the UT-SSP will be to utilize stratified random sampling to provide an increasing confidence that at least one of the strips from the worst $5 \%$ within the entire population of tanks will be observed. In addition, over the service life of any ISI tank, the increasing number of strips will provide greater confidence that at least one strip will have been amongst the worst $5 \%$ of the strips within that tank with the assumption that the worst area within a tank can be gauged by pitting.

Furthermore, the UT-SSP examinations will be used to validate current models that trend general wall thinning and pitting. Data obtained from inspection of the strips include pit depth measurements and wall thickness, the latter of which is 
determined by averaging thousands of measurements over one-foot segments of each strip. From previous UT inspections, pit depths greater than 15 mils were identified along with their location on the corresponding strips. Averaged wall thickness data was stratified by either lower, middle, or upper plate locations (starting about $2 \mathrm{ft}$ from the tank floor) and statistically analyzed for trending and tank lifetime projections.

\section{STATISTICAL METHODOLOGY}

There are five aspects to the statistical methodology in the UT-SSP:

1) Select random strips for UT inspection to assure unbiased statistical results,

2) Determine the number of strips to inspect when considering all 27 Type III/IIIA ISI tanks to have high confidence that at least one of the "worst" (i.e., pit depth or wall thickness) $5 \%$ will be examined,

3) Determine the confidence gained by increased inspection within any single tank,

4) Determine the upper tolerance limit for pits and compare to the pit depth acceptance criteria, and

5) Determine the tolerance limit for the corrosion rate by evaluating the change in tank wall thickness over time and compare to the wall thinning acceptance criteria.

This multifaceted approach to evaluating the integrity of the ISI LW tanks will ensure their safe and continued reliable use throughout their in-service lifetimes.

\section{1) Random Sampling}

From the perspective of corrosion behavior, general corrosion rates should be low, and pitting should be mitigated in all the CCP tanks. Confirmation of the effectiveness of the CCP is achieved through a random sampling plan. In particular, stratified random sampling is conducted for each tank to complement UT data from past inspections, providing an increasing confidence in the integrity of the ISI tanks over time. Implemented in 2010, the sampling plan includes one strip randomly selected within each non-overlapping 90 degree quadrant of each tank. In addition, a fixed strip has been selected for UT inspection that will be used to model corrosion and/or pit depth growth with respect to time. The fixed strip selected for continued inspection in most cases was first inspected thirty to forty years ago and correlates with the beginning of the tank service history.

The majority of pre-2010 data was obtained from strips located near one of the outer tank wall access areas referred to as "risers." Because of the distribution of pit and wall thickness data points across various plate areas, sheets of steel, and tank height levels, it is reasonable to treat these strips as a random selection of strips. Current UT technology allows any strip to be inspected within a tank, unless obstructions inherent to the structure of the tank prevent access to that strip. If an obstruction prevents inspection of a particular strip, the closest neighboring strip will be inspected. The pre-2010 data will be complemented with the UT-SSP data as strips are inspected.

\section{2) Confidence Curves for Sampling All ISI LW Tanks}

Confidence curves for UT inspection of strips from all ISI LW tanks are based on application of the hypergeometric distribution. The target population is all strips contained within the 27 ISI LW tanks. Because each tank consists of approximately 360 strips, the 27 ISI tanks can be thought of as a collection of 9,720 strips. The hypergeometric distribution for the probability of obtaining $x$ strips from the worst $5 \%$ of the population in a random sample of size $n$ is:

$$
\begin{aligned}
P(x)= & \frac{\left(\begin{array}{l}
D \\
x
\end{array}\right)\left(\begin{array}{l}
N-D \\
n-x
\end{array}\right)}{\left(\begin{array}{l}
N \\
n
\end{array}\right)}= \\
& \frac{\left(\frac{D !}{x !(D-x) !}\right)\left(\frac{(N-D) !}{(n-x) !(N-D-n+x) !}\right)}{\frac{N !}{n !(N-n) !}},
\end{aligned}
$$

where $a \leq x \leq b \quad a=\max [0, n-(N-D)]$, $b=\min [D, n]$, and $N$ represents the number of strips in the population, $D$ represents the number of worst strips $D=0.05(N)$, and $N-D$ represents the remaining number of strips in the population. The number of strips selected for UT is represented by $n$, of which $x$ are from the worst $5 \%$ of all strips and $n-x$ are the remaining number of strips in the sample. The number of worst strips $x$ in the sample cannot exceed the minimum of $n$ and $D$ [equivalently, $\min (n, D)]$. For any positive integer $\mathrm{k}, k !=(k)(k-1)(k-2) \ldots 1$ and is called $k$ factorial (for $k=0,0 ! \equiv 1$ by definition).

The probability of inspecting no strips from the worst $5 \%$ is determined from $P(x)$ with $\mathrm{x}=0$ and simplifies to

$$
\begin{aligned}
P(0)= & \left(\frac{N-D}{N}\right)\left(\frac{N-1-D}{N-1}\right)\left(\frac{N-2-D}{N-2}\right) \cdots \\
& \left(\frac{N-n+1-D}{N-n+1}\right)
\end{aligned}
$$

The probability of inspecting at least one strip from the worst $5 \%$ of all strips is:

$$
P_{1+}=1-P(0)
$$

The number of strips selected for UT, $n$, should be selected so that $P_{1+}=1-P(0) \geq 0.999$ to meet the $99.9 \% / 5 \%$ criteria. 
In this paper, $100\left(P_{1+}\right)$ is referred to as "confidence."

To have sampled at least one strip from the worst $5 \%$ with $99.9 \%$ confidence, 134 strips would have to be randomly selected and inspected. Stratified random sampling has been shown to meet this criterion by inspecting at least 5 strips per each of the $27 \mathrm{LW}$ tank. The stratified random sampling has been implemented within each tank by specifying that one strip per quadrant be randomly selected and UT inspected. The current sampling schedule over the next 7-10 years includes 121 randomly selected strips. When complemented with one fixed strip per tank, this will assure that at least one strip from the worst $5 \%$ will have been inspected with at least $99.9 \%$ confidence. In addition, the data to date will be statistically compared with and possibly combined with the UT-SSP data if statistically appropriate. A confidence curve (Figure 7) shows the rate at which the confidence increases as the number of inspected strips increases, eventually reaching $99.9 \%$ confidence as additional strips are tested.

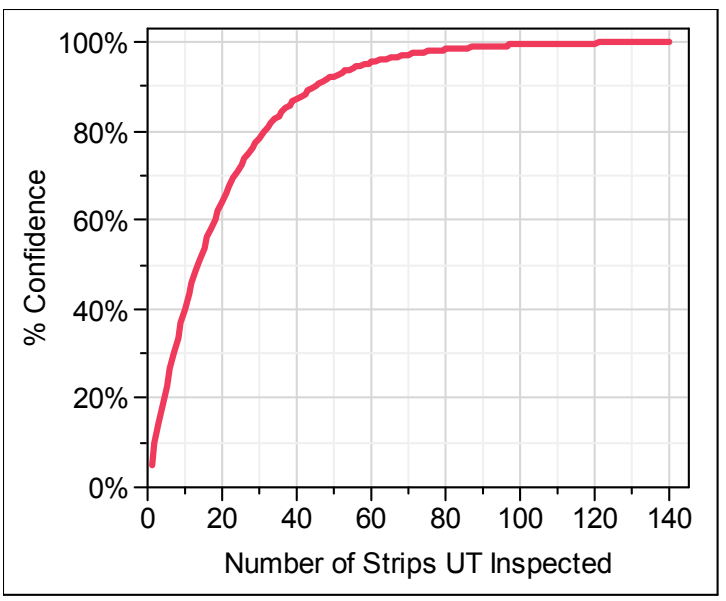

Figure 7: Confidence Curve for the Probability of Inspecting at Least One Strip from the Worst 5\% across All Tanks.

\section{3) Confidence Curves for Individual ISI Tanks}

Using the hypergeometric probability calculation (Equation 3), for an individual tank consisting of approximately 360 strips, 112 strips $(31 \%)$ would have to be inspected to have sampled at least one strip from the worst 5\% with $99.9 \%$ confidence. While the number of strips for UT inspection that arises from the hypergeometric distribution to attain $99.9 \% / 5 \%$ for all ISI tanks collectively is attainable (>134 strips), the number of strips for UT inspection required for any individual tank is not (112 strips).

The hypergeometric calculation (Equation 3) was not based on assumptions related to the attributes that may designate a strip as one of the worst $5 \%$. A classification attribute for the "worst" strips in a tank may be based on the pit distribution. Because it is not realistic within the service life of a single tank to inspect 112 individual strips, it is imperative that a classification attribute be utilized in order to determine the confidence gained by increased inspection within a tank.

Using existing UT data, it was possible to define strips with regard to pitting as being amongst the "worst" in a tank. A pit distribution was created using 38 strips, 11 of which exhibited no detectable pitting. Measurable pits depths ( $>15$ mils) from the remaining 27 strips were compiled in a distribution plot (Figure 8).

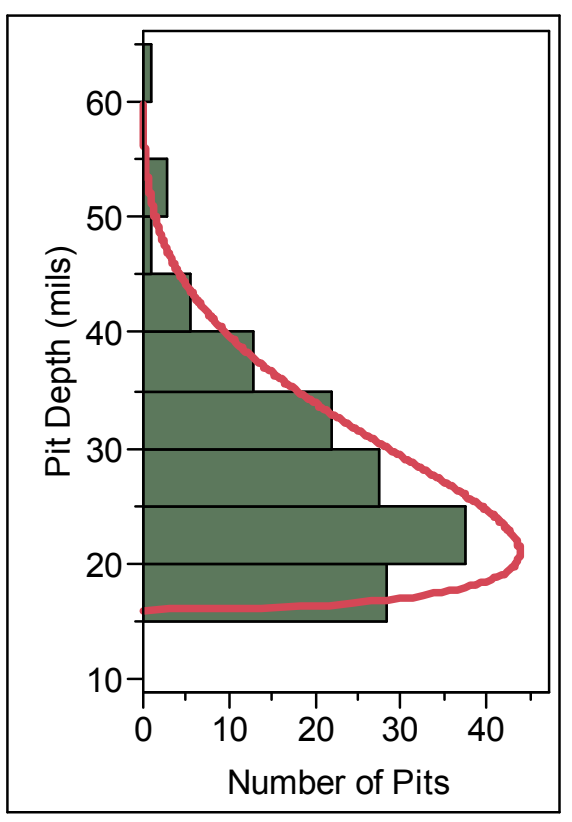

Figure 8: Pit Depth Distribution (mils) across All Tanks.

The pit distribution with an average of 26.6 mils and a standard deviation of 8.34 mils includes measurements ranging from 16 to 63 mils (Figure 8). Approximately 91\% (137 data points) of the measurable pit depths are from lower plates, $9 \%$ (13 data points) from middle plates, and $0.6 \%$ (1 data point) from upper plates. The largest $7 \%$ of pits are from the lower plate. As such, the lower plate data were selected for defining the "worst" strips.

The strips were divided into one-foot vertical segments, and the maximum pit depth per segment $\left(\mathrm{M}_{\mathrm{X}} \mathrm{PD}\right)$ was determined. A distribution of the $\mathrm{M}_{\mathrm{X}} \mathrm{PD}$ values ( $>15$ mils) by plate is displayed in Figure 9, and the summary statistics are displayed in Table 1. The distribution for the lower plate across inspected tanks is displayed in Figure 10, and the summary statistics are displayed in Table 2. There is no statistical difference in the average $\mathrm{M}_{\mathrm{X}} \mathrm{PD}$ across all six tanks. Equal variation in $\mathrm{M}_{\mathrm{X}} \mathrm{PD}$ across the tanks is also a reasonable assumption. Therefore, the data were combined across all tanks in representing the pit depth distribution. Approximately $85 \%$ of the one-foot segments had pit depths less than or equal to 15 mils.

The lower plate measurements were ordered according to their pit depths. The greatest $5 \%$ of the $\mathrm{M}_{\mathrm{X}} \mathrm{PD}$ measurements were from 11 of the 38 strips, lending a 0.29 probability of being found on a randomly selected and UT inspected strip. 
Using this probability in the hypergeometric calculation (Equation 3), the confidence curves was regenerated in order to determine the confidence for sampling strips within a single tank containing 360 strips (Figure 11). It is evident that inspecting 5 strips will give $95 \% / 5 \%$ (95\% confidence of inspecting one of the worst $5 \%$ of strips). In order to obtain $99.9 \% / 5 \%$, approximately $3.3 \%$ of the tank (12 strips) must be inspected. With the UT-SSP and the 7-10 year inspection schedule per tank, it is possible to obtain the $95 \% / 5 \%$ level for all ISI tanks during the next inspection cycle. For tanks with the longest expected service lives, $99.9 \% / 5 \%$ will be reached on the third inspection cycle.

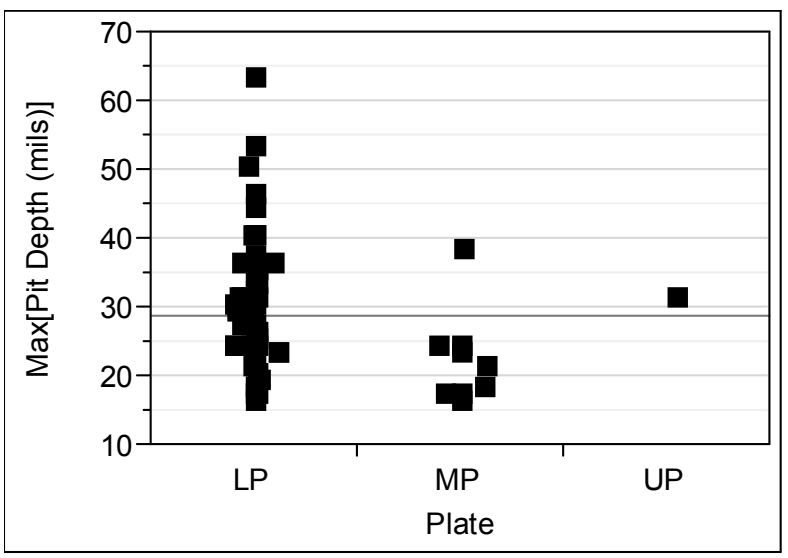

Figure 9: Maximum Pit Depth (mils) per 1 ft Segment by Plate.

Table 1: Summary Statistics for Maximum Pit Depth (mils) per 1 ft Segment by Plate.

\begin{tabular}{|l|l|l|l|}
\hline Level & $\begin{array}{l}\text { Number } \\
\text { of Pits }\end{array}$ & $\begin{array}{l}\text { Average } \\
\mathbf{M}_{\mathbf{X}} \mathbf{P D} \\
\text { (mils) }\end{array}$ & $\begin{array}{l}\text { Std Dev } \\
\mathbf{M}_{\mathbf{X}} \mathbf{P D} \\
\text { (mils) }\end{array}$ \\
\hline LP & 52 & 29.8 & 9.69 \\
\hline MP & 9 & 22.0 & 6.78 \\
\hline UP & 1 & 31.0 &. \\
\hline
\end{tabular}

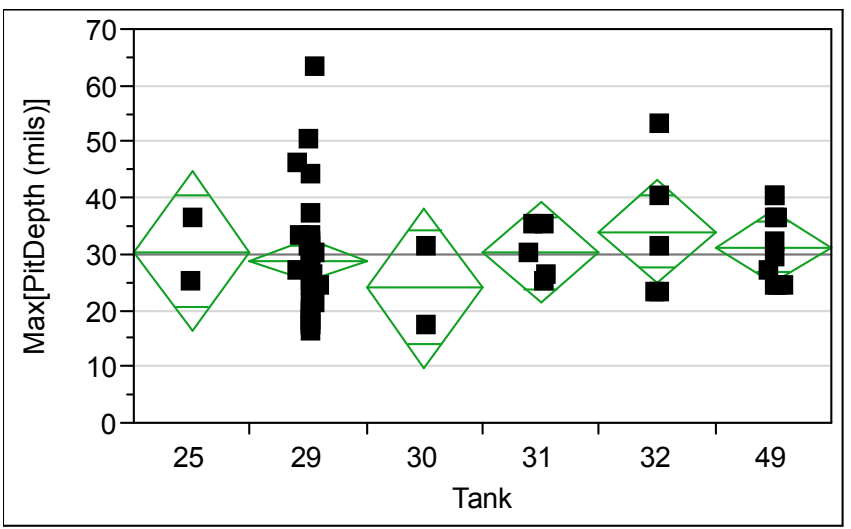

Figure 10: Maximum Pit Depth (mils) for the Lower Plate.

\section{4) Tolerance Limits for Pit Depth}

Pitting is a localized form of corrosion that occurs on passivated metal surfaces exposed to aggressive chemical environments. The pitting process involves the breakdown of the passive oxide film and subsequent anodic dissolution of

Table 2: Pit Depth (mils) Summary Statistics using the Lower Plate Maximum Pit Depths.

\begin{tabular}{|l|l|l|l|}
\hline Tank & $\begin{array}{l}\text { Number of 1 } \\
\text { foot segments }\end{array}$ & $\begin{array}{l}\text { Average } \\
\text { (mils) }\end{array}$ & $\begin{array}{l}\text { Std Dev } \\
\text { (mils) }\end{array}$ \\
\hline 25 & 2 & 30.5 & 7.78 \\
\hline 29 & 28 & 28.9 & 11.08 \\
\hline 30 & 2 & 24.0 & 9.90 \\
\hline 31 & 5 & 30.2 & 4.76 \\
\hline 32 & 5 & 34.0 & 12.73 \\
\hline 49 & 10 & 31.2 & 6.49 \\
\hline
\end{tabular}

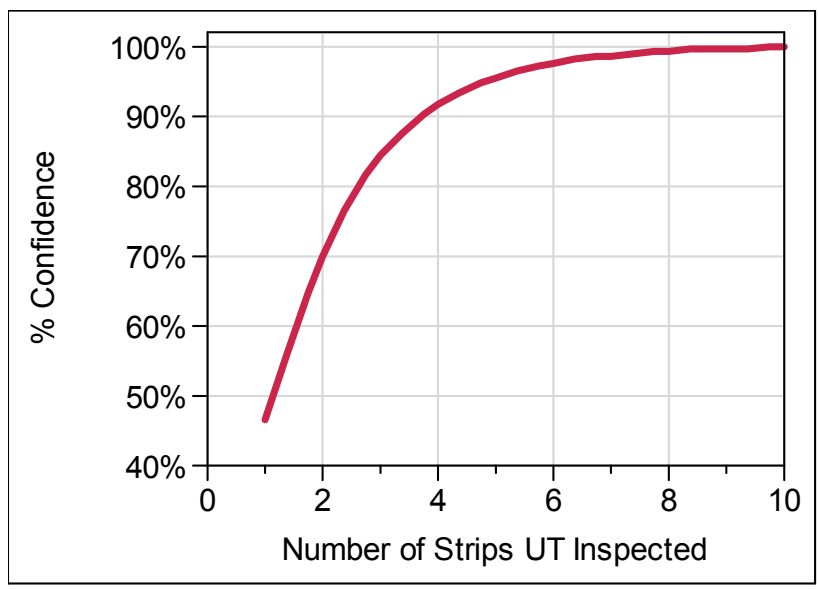

Figure 11: Confidence Curve for the Probability of Inspecting at Least One Strip from the Worst 5\% within Any Tank.

the metal at a local site, while the remainder of the surface remains protected by the film. The initiation and propagation of pits appears to be a random process. The apparent growth rate for a given pit may change as a result of fluctuations in the local chemistry that influence the metal dissolution and repassivation reactions. Deep pits are of greatest concern, if unmitigated, because they may result in reduced service life of the LW tank, and lead to the potential loss of confinement. While pitting does not impact the structural stability of the overall structure, a through-wall pit will lead to leakage of waste. Pitting corrosion is of concern because pit sites not only may act as leakage points, but also may be precursors to stress corrosion cracking.

Pit depths, established by UT, are subject to variables that cause uncertainty, including the repeatability of metric location, time between measurements, different transducers, and different inspectors. Therefore, a statistical analysis was 
performed to determine an upper tolerance limit for $\mathrm{M}_{\mathrm{X}} \mathrm{PD}$ in the SRS LW tanks. The tolerance limit gives an indication of extreme values of pit depth for the current condition of the tank walls. The upper tolerance limit for pit depth, calculated in this section, will then be compared to the SRS action levels for pitting. If the upper tolerance limit for pit depth exceeds the action level, appropriate actions could include more frequent examinations or inspections of increased tank surface area.

A statistical tolerance interval covers a fixed proportion of the population with a stated confidence. The endpoints of a tolerance interval are called "tolerance limits." Statistical tolerance limits for the normal distribution are calculated as $\bar{x}-k s$ for a lower limit, or $\bar{x}+k s$ for an upper limit, where $\bar{x}$ is the sample average, and $s$ is the sample standard deviation. The $k$ value is based on the non-central tdistribution, and is tabulated in various sources ${ }^{3}$ as a function of the amount of data available, the desired confidence (e.g., $95 \%$ ) and the percentage of the distribution to be bounded (called "coverage") by the calculated limit (e.g., 99\%).

As a first step in calculating the upper tolerance limit for pit depth, the $\mathrm{M}_{\mathrm{X}} \mathrm{PD}$ data for measurable pits $>15$ mils were used. The lower plate data showed greater average $\mathrm{M}_{\mathrm{X}} \mathrm{PD}$ (29.8 mils vs. 22.0 mils) and a higher standard deviation (9.69 mils vs. 6.78 mils) than the middle plate data. As such, use of the lower plate data provided a greater, more conservative upper tolerance limit for the maximum pit depth per one foot segment.

The lognormal distribution was used to model the $\mathrm{M}_{\mathrm{X}} \mathrm{PD}$ measurements (Figure 12). Lognormal distributions have a central role in risk assessment. Many physical, chemical, biological, toxicological, and statistical processes tend to create random variables that follow lognormal distributions ${ }^{4}$. A variable $\mathrm{X}$ is lognormally distributed if $\mathrm{Y}=\ln (\mathrm{X})$ is normally distributed ("ln" denotes the natural logarithm, log base 10 is also used).

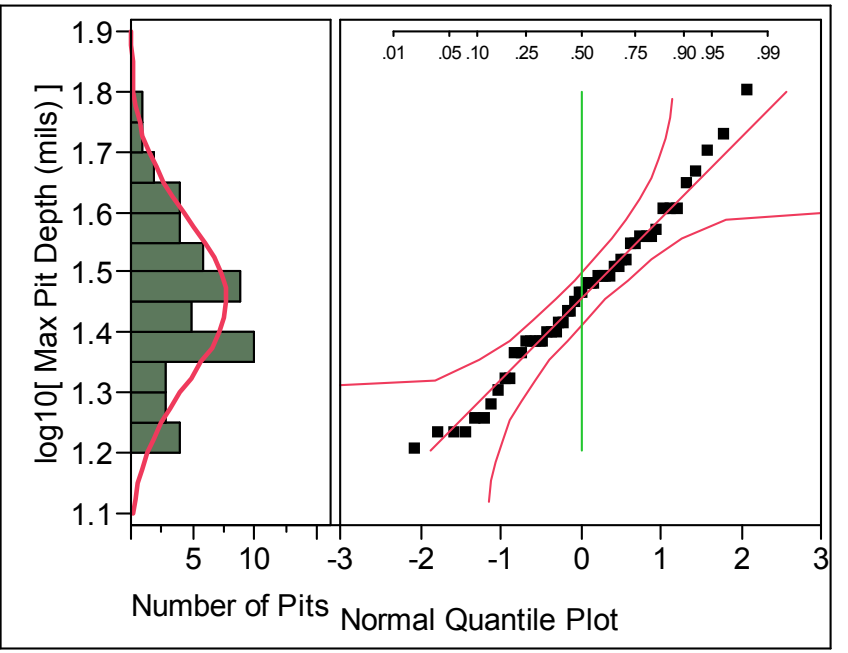

Figure 12: Normal Distribution Fit to Maximum Pit Depth on the log10 Scale for the Lower Plate Only.
On the log base 10 scale, the average is 1.454 and the standard deviation is 0.134 for the $52 \mathrm{M}_{\mathrm{X}} \mathrm{PD}$ values from the LP.

The upper tolerance limit with $95 \%$ confidence limit for $99 \%$ coverage is: $\bar{x}+k s=1.454+2.85 \times 0.134=1.836$ on the $\log 10$ scale $(k=2.85)$. As such, the tolerance limit converts to $10^{1.836}=68.5$ mils. A number of other distributions (Weibull, Gamma, 3 parameter lognormal, Largest Extreme Value) have been shown to fit the pit depths equally well. Their upper tolerance limits with 95\% confidence limit for $99 \%$ coverage range between 69.9 mils to 75.8 mils. All the calculated upper limits are well below the action level threshold of 219 mils for the lower plate. Tolerance limits will be updated with additional UT inspection over time and compared with the acceptance criteria.

\section{5) Tolerance Limits for General Corrosion Rate}

General corrosion is the uniform attack of a metal surface and results in the gradual thinning of a structure. The rate of general corrosion of a tank is established by UT measurements of wall thickness obtained at a minimum of two points in time, separated by a number of years, during tank service. The wall thickness measurements were trended over time to estimate the corrosion rate (slope over time). Assuming that the corrosion rate remains constant, the wall thickness may be projected as a function of time.

As for pit depth projections, the uncertainty in UT measurements must be accounted for in service life projections. In order to determine the lower tolerance limit (decreasing wall thickness) for the corrosion rate of SRS LW tanks, wall thickness data (UT) ranging from 1973 to 2009 were utilized.

Due to measurement uncertainty, approximately $13 \%$ of estimated corrosion rates (slopes) are slightly positive (increasing wall thickness). This is an artifact of slight UT location differences, measurement uncertainty, and a lack of active corrosion. They were set to zero before conducting the statistical analyses. An illustration of corrosion rates for lower plates (Figure 13) shows two rates whose slopes are steep relative to other lower plate rates (Tank 48, Riser P-13, with a rate of -1.62 mils/year, and Tank 51, Riser P-10, with a rate of -1.18 mils/year). The waste in Tank 48, a Type IIIA LW tank, has been in compliance with the corrosion control program for essentially its entire service history. Given the relatively high inhibitor concentration in the waste, the lower plate of the tank would be expected to show limited, if any attack. Tank 51 is also a Type IIIA LW tank that was placed in-service in 1986. The tank level has varied over time such that all three plates (i.e., upper, middle, and lower plates) have been exposed. In contrast to Tank 48, Tank 51 has experienced heavy use. Also, because of the relatively high inhibitor concentration in the waste, the corrosion rate would be expected to be slight.

The Tank 48/P-13 data was considered to be an extreme case, differing from the remaining data set much like an 
outlier. Its data, including its middle and upper plate measurements, were eliminated from the set. However, the data from Tank 51/P-10 was not eliminated from the data set, as it varied less extremely. Nevertheless, it still had a large impact on the statistical results for the lower plate. Corrosion rates were estimated separately for each Tank/Riser combination and plate (Figure 14, Table 3).

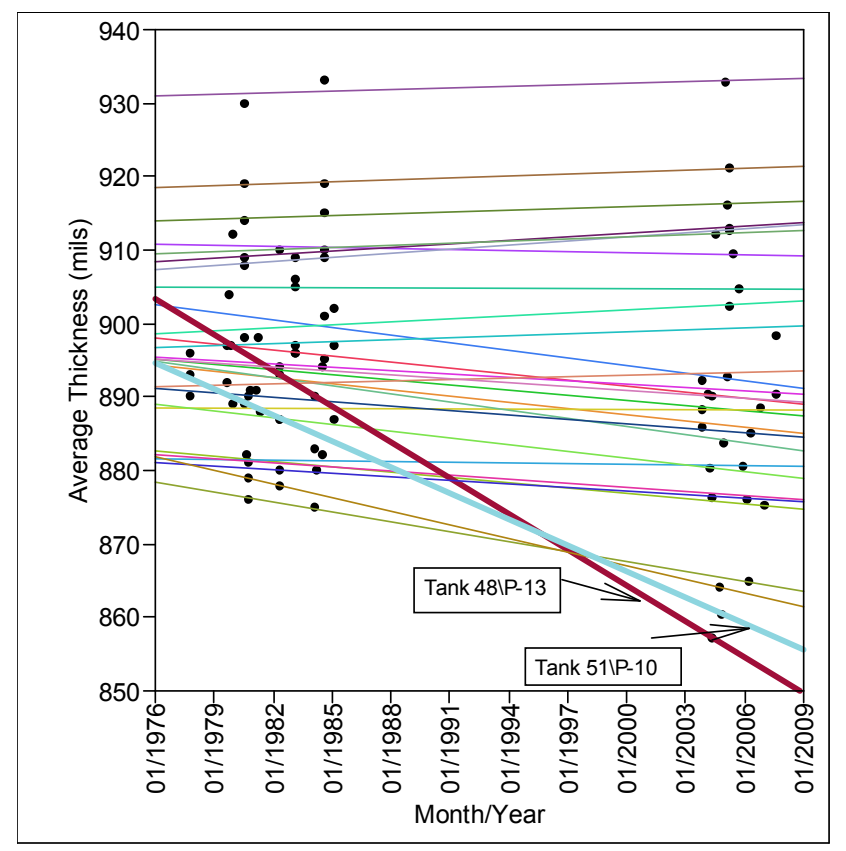

Figure 13: Wall Thickness (mils) by Month/Year for the Lower Plate.

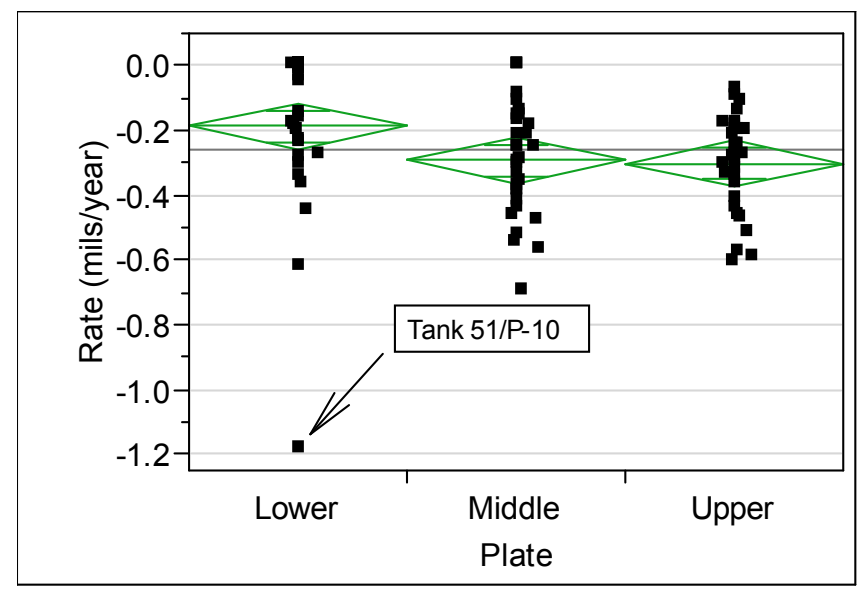

Figure 14: Dot Plots with Mean Diamonds for Corrosion Rates by Plate.

Tolerance limits for corrosion rates, based on the three parameter lognormal distribution, were calculated for each plate and for all plates combined (Table 3). The lower tolerance limit with $95 \%$ confidence for $99 \%$ coverage for all plates combined is -1.06 mils/year (Figure 15), while that for the lower plate alone is -1.64 mils/year. Recall that the corrosion rate for Tank 48/P-13 was -1.62 mils/year. When general corrosion is the primary degradation mechanism, the remaining service life projection is defined as the time necessary to achieve minimum wall thickness within American Society of Mechanical Engineers (ASME) acceptance criteria for normal or seismic loads.

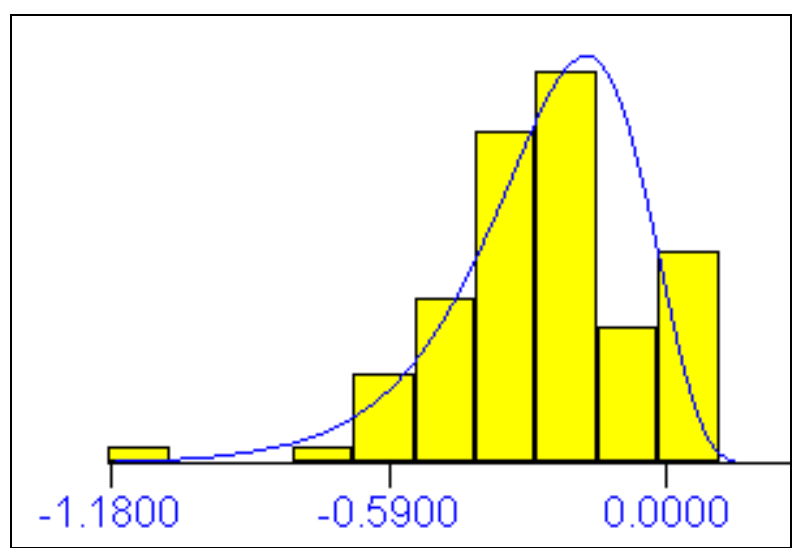

With $95 \%$ confidence, more than $99 \%$ of the corrosion rate distribution is above -1.06 mils/year.

Figure 15: Lower Tolerance Limit for Corrosion Rate (mils/year) from Distribution Analyzer Software .

Table 3: Lower Tolerance Limits for Corrosion Rate by Plate.

\begin{tabular}{|l|l|l|l|l|}
\hline Plate & Number & Average & Std Dev & $\begin{array}{l}\text { Lower 95\%/99\% } \\
\text { Tolerance Limit } \\
\text { (mils/year) }\end{array}$ \\
\hline Lower & 28 & -0.19 & 0.255 & $-1.64^{(*)}$ \\
\hline Middle & 31 & -0.29 & 0.176 & -0.91 \\
\hline Upper & 31 & -0.30 & 0.145 & -1.00 \\
\hline Overall & 90 & -0.26 & 0.200 & -1.06 \\
\hline
\end{tabular}

${ }^{(*)}$ Lower Tolerance Limit is -0.87 mils/year if the Lower Plate corrosion rate when Tank 48/P-13 is eliminated.

To meet this requirement, calculations demonstrated that Type III/IIIA LW tanks could experience 100 mils of wall reduction from the nominal thickness. Additionally, wall thinning $>10 \%$ nominal had been set internally at SRS for more frequent examinations to evaluate degradation based on the framework of ASME Section XI ${ }^{6}$. The area inspected would double if a wall thinning rate of $20 \%$ nominal was exceeded, and additional area would be inspected in a tank with similar history and chemistry. Tolerance limit projections for LW tank in-service years to the $10 \%$ and $20 \%$ thresholds are displayed in Table 4.

The corrosion allowance for Type III/IIIA LW tanks is defined as the difference between the total thickness as fabricated and thicknesses of 100 mils below nominal design. 
Table 4: Lower Tolerance Limit for Years to Threshold from the In-Service Date.

\begin{tabular}{|c|c|c|c|c|c|c|c|}
\hline \multirow[t]{2}{*}{ Coverage } & \multirow{2}{*}{$\begin{array}{c}\text { Corrosion Rate } \\
\text { 95\% Confidence } \\
\text { Lower Limit } \\
\text { (mils/year) }\end{array}$} & \multicolumn{2}{|c|}{ Top Plate } & \multicolumn{2}{|c|}{ Middle Plate } & \multicolumn{2}{|c|}{ Lower Plate } \\
\hline & & $\begin{array}{c}\text { Years to } \\
10 \% \text { Limit }\end{array}$ & \begin{tabular}{|c|} 
Years to \\
$20 \%$ Limit \\
\end{tabular} & $\begin{array}{c}\text { Years to } \\
10 \% \text { Limit }\end{array}$ & \begin{tabular}{|c|} 
Years to \\
$20 \%$ Limit
\end{tabular} & \begin{tabular}{|c|} 
Years to \\
$10 \%$ Limit
\end{tabular} & $\begin{array}{c}\text { Years to } \\
20 \% \text { Limit } \\
\end{array}$ \\
\hline $95.00 \%$ & -0.74 & 68 & 135 & 84 & 169 & 118 & 236 \\
\hline $99.00 \%$ & -1.06 & 47 & 94 & 59 & 118 & 83 & 165 \\
\hline $99.50 \%$ & -1.20 & 42 & 83 & 52 & 104 & 73 & 146 \\
\hline $99.90 \%$ & -1.54 & 32 & 65 & 41 & 81 & 57 & 114 \\
\hline $99.99 \%$ & -2.06 & 24 & 49 & 30 & 61 & 42 & 85 \\
\hline
\end{tabular}

This criterion does not imply failure of containment, rather the lower wall-thinning limit at which a tank no longer meets ASME code seismic requirements for maximum specific gravities of fluids and fill heights. The within and between tank variability (Table 5) for the corrosion rate overall tanks and plates were estimated using analysis of variance.

Using these estimates, the percent relative error for the mean corrosion rate within a tank was calculated as:

$$
\% \operatorname{Re} l E r r_{w}=100 \frac{s_{w}}{\sqrt{n_{w}}|\bar{x}|}
$$

and the relative error for the mean corrosion rate across all tanks was calculated as:

$$
\% R \text { e } l \text { Err }=100 \sqrt{\frac{s_{b}^{2}}{n_{b}}+\frac{s_{w}^{2}}{n_{b} n_{w}}} /|\bar{x}|
$$

where $n_{b}=23$ tanks, wall thickness was measured using UT on up to $n_{w}=5$ strips inspected per tank, and $\bar{x}$ is the average corrosion rate (Figure 16). The relative error overall tanks was $12 \%$ for inspecting one strip per tank and viewed as acceptable. There is only a marginal decrease in the relative error across all tanks if additional strips per tank are inspected. Therefore, it is recommended that one stationary strip per tank be UT inspected at each periodic inspection. Six stationary strips would be required to reach the same precision for a within tank corrosion rate. Per tank corrosion rates are not statistically attainable for lack of historical data.

\section{Table 5: Estimates for Within Tank and Between Tank Corrosion Rate Variability.}

\begin{tabular}{|l|l|}
\hline Source of Variability & Standard Deviation \\
\hline Between Tanks & $s_{b}=0.293$ mils/year \\
\hline Within Tanks & $s_{w}=0.157$ mils $/$ year \\
\hline
\end{tabular}

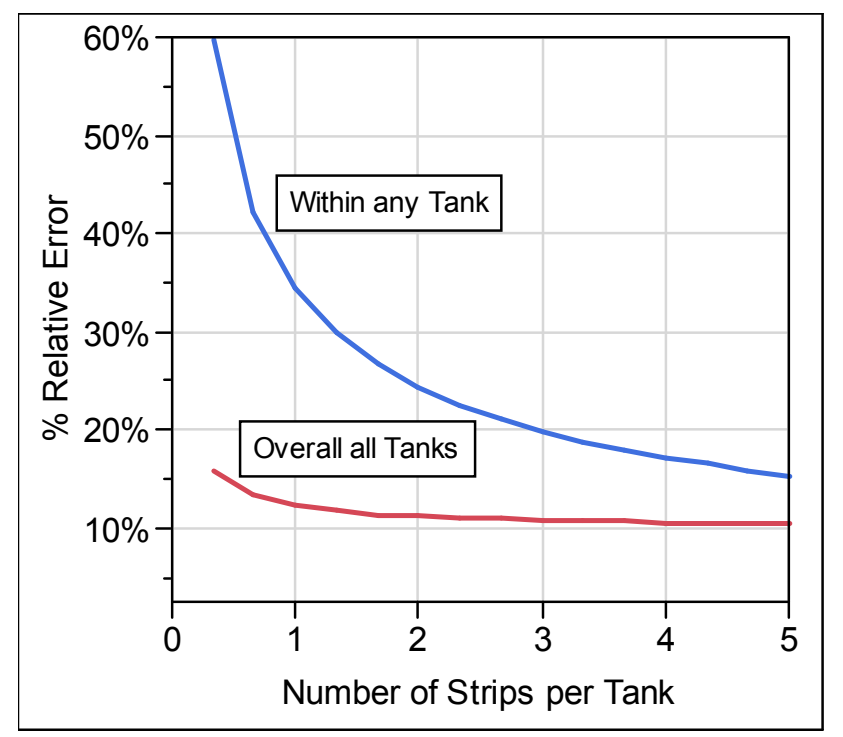

Figure 16: Percent Relative Error in the Mean Corrosion Rate vs. Number of Strips Inspected.

\section{CONCLUSIONS}

As a vehicle for the interim storage of $\mathrm{LW}$, these tanks are an integral part of defense and environmental waste remediation. Maintaining and ensuring the integrity and safety of the tanks is imperative. This may be accomplished with routine inspections and an active corrosion control program. However, because of their enormous size and accessibility constraints, inspections are challenging and costly. Moreover, the time required for extensive inspections would exceed the in-service tank lifetimes. Therefore, it is impractical that even 5\% of one LW tank should be inspected annually. The sampling strategy presented here enables the ISI program to overcome these barriers and develop profiles of individual tanks that collectively provide a high confidence in the safety and integrity of the overall tank population. The results demonstrate that the service life of the LW tanks will greatly exceed their operational needs. 
With the use of UT technology and statistical sampling and analysis, there is a high confidence that corrosion and pitting are observable and can be quickly mitigated to prevent compromise.

The inspection of each of the 27 tanks accounts for the variable chemical conditions within the population and lessens the impact of individual biases. Utilizing stratified quadrant sampling in coordination with the baseline strip within each tank provides randomness while still considering the enormous girth of the tanks, preventing reliance on any assumptions of circumferential uniformity. The use of vertical strips ensures that thinning and pitting are observed over the entire height of the tank, accounting for the dynamic volume, waste stratification, and constitution of a LW tank over decades of service.

With stratified random sampling in conjunction with the baseline strip, 5 strips are inspected in each tank per inspection period. Over seven to ten years, more than 134 strips would be inspected across the LW tank population. Over the service life of the LW tanks, this sampling plan builds an increasingly high confidence that at least one strip observed is among the worst $5 \%$ of the population.

If an inspected strip should exhibit data that is very different from the rest in the population, the statistical samples will be augmented with judgmental sampling, using engineering knowledge to target strips that could have the greatest potential for degradation. By combining judgmental sampling with the ISI sampling plan presented herein, the collection of random and repeat measurements as the tank ages will reach high asymptotic confidence that corrosion in the tanks is observable and mitigated and that the safety and integrity of the tanks is secured for the duration of the tanks' service lifetimes.

\section{ACKNOWLEDGEMENTS}

This document was prepared in conjunction with work accomplished under the U.S. Department of Energy Contract No. DE-AC09-08SR22470. The authors would like to acknowledge and thank B. J. Wiersma of SRNL and M. E. Maryak of SRR for their advice and consultations during the preparation of this paper.

\section{REFERENCES}

${ }^{1}$ DOE, "Stabilization, Packaging, and Storage of PlutoniumBearing Materials," DOE-STD-3013, U.S. Department of Energy.

2 Peppers, L., et. al. (2009). Selection of 3013 Containers for Field Surveillance: LA-14310, Revision 1, LA-14395. Issued: April 2009. http://www.osti.gov/bridge/product.biblio.jsp?osti id=9574 $\underline{84}$

3 Odeh, R.E. and Owen, D.B. (1980). Tables for Normal Limits, Sampling Plans, and Screening. Marcel Dekker, Inc., NY.

${ }^{4}$ Hattis, D.B. and Burmaster, D.E. (1994). Assessment of Variability and Uncertainty Distributions for Practical Risk Assessments, Risk Analysis, Volume 14, Number 5, pp 713 -730 . Distribution Analyzer, Ver. 1.3, Taylor Enterprises, Inc., Libertyville, IL. www.variation.com.

${ }^{6}$ BPV Code: Section XI - In-service Inspection of Nuclear Power Plant Components. 